VS Publications

Alford Council of International English \& Literature Journal(ACIELJ)

Impact Factor:4.401(SJIF)An International Peer-Reviewed English Journal

www.acielj.com

Vol-3,Issue-2 ,2020

ISSN:2581-6500

\title{
HISTORY OF CONTEMPORARY INDIAN ENGLISH POETRY :AN APPRAISAL(A STUDY IN BRIEF )
}

\section{Dr.Suresh Chandra Pande \\ Uttarakhand,India}

"To know history is to know life". Herodotus

\section{Abstract:}

PCK Prem (Katoch) of Himachal Pradesh(India) is a bilingual writer. $\mathrm{He}$ writes in English and Hindi with equal ease and poise. So far he has authored more than fifty-six books .He is a poet, novelist, short-story writer \& a critic well known and well acclaimed in our contemporary literary scene. His poetry collections like 'Enigmas of An Identity'(1990) and 'Those Distant Horizons' (1993) bear a peculiar attractiveness ,charm and charisma. While his novels such as 'A Night Of Storms'(1996) and 'Not Their Lives'(2003) dynamically entice his readers for a definite period of time in strong ingenious fold. His books on English Literary Criticism together offer a fresh indigenous bouquet of thematic motifs, analytical pursuits and prevalent trends/drifts.His latest work on criticism widened into two volumes I \& II, fascinatingly provides a complete history of Indian English Poetry, harking back as far as to the mutiny of 1857 , besides contemporary predicament and presentday angst relevant in existential context. The author has done tremendous toil in his study of poets both great and small and has bequeathed almost equal status to all irrespective of class and cadre.A careful study of these two volumes reveal altogether a fine assessment of poets, their peculiar knack ,penchant and flair flavored side by side by regional idiosyncracies ,cynicism, eccetricities even illogical features. I ,however , have done my best to assimilate the entire gamut of poetic output in my brief study that incorporates almost all salient features those appear in authors extensive appraisal

Keywords :Age, Assessment, Chronology ,Column, Caliber, Gamut, Government, History, Holy, Literature, Poetry ,Penchant.

History is an awning term. It is related to past as well as to memory ,discovery ,collection ,organization ,presentation and interpretation of information/s about long-gone events .In the field of academic discipline a narrative is used to examine and analyze in succession the sequence of past events. It seeks to determine objectively the pattern of cause and effect so as to arrive at the chosen finale. Historians oftentimes debate the nature of history and its usefulness by arguing together the study of the discipline as an end in itself or as a way of providing perspective on existing problems of the present .As a rule, the academic study of history forms a major discipline in university or higher study society. In view of the fact of these statements "History Of 
VS Publications

Alford Council of International English \& Literature Journal(ACIELJ)

Impact Factor:4.401(SJIF)An International Peer-Reviewed English Journal

www.acielj.com

Vol-3,Issue-2,2020

ISSN:2581-6500

Contemporary Indian English Poetry :An

Appraisal" of PCK Prem deserves esteem so demands an analytical and reflective inquiry .Here I am making a humble attempt to explore the multifarious dimensions of Indian English Poetry extensively studied and brought to light by an academic turned bureaucrat or vice versa.

Poetry, more particularly Indian English Poetry, as the author himself admits, is a beautiful and radiant manifestation of ancient India's flourishing classical literature notable for its excellence and enduring quality. Along with literature varieties pertaining to civilization, culture and tradition of ancient India gains a munificent place in the works of Indian English Poets ever since its inception .The background, upbringing, source and supply of this poetry ,molded time and again, by the vibrant and all encompassing universal ideals of ancient India's enlightening cosmology, stoked up further by syntactic, scientific ,metaphysical, material and moral codes brought by colonial masters ,appears genuinely twice-born .(*) So, necessitates a cautious and careful interpretation. That is why, being a real blend of the two-the East and the West ,this poetry, unique in itself, seems to put side by side, apparently contradictory yet complimentary beliefs. Although formative stages of development show ,here and there, quaint and queer pictures of this assimilation yet the overall picture is aesthetically pretty and charismatic .What matters most, is the lofty and exalted status of this genre of poetry that whirl through the flames and ecstasies of creation.
The historic two volumes, voluminous in size and epical in dimension, analyze and evaluate precisely in simple tone and tenor the intent and purpose of Indian English Poetry : its journey from an uncertain and craggy ambit to an idyllic epoch of sanguine and peaceful existential angst .The introductory part that covers 15 pagesfrom 15 to 30 in first volume of 740 pages taken together and13 to 28 in second volume comprising in all 679 pages, comprehensively yet eruditely narrates, in parts, the brief history of India English Poetry from $19^{\text {th }}$ century onward till present. Explicating together the endorsement and sponsorship of English by the then ruling heads of government and its far-reaching repercussions on contemporary Indian masses ,particularly those who used to practice the art and genre of poetry, the author well compacts the whole lot in fourteen chapters followed by an exclusive epilogue. He for his and for the expediency of readers further concentrates his discussion segment-wise : the first segment includes poets born after1920 and the second after 1950.In this way, in both volumes by way of an extensive study, he ably and systematically pigeonholes, for ingenuous evaluation, the creative works of 185 poets and 50 women poets all in all. He after meticulous research delves deep to categorizes thematically as well as chronologically almost all justifiable Indian English Poets.

How pretty candidly he comes clean to acknowledge- "To the unknown and known poets ,I sincerely feel apologetic if I fail to do justice .Perhaps, 
VS Publications

Alford Council of International English \& Literature Journal(ACIELJ)

Impact Factor:4.401(SJIF)An International Peer-Reviewed English Journal

www.acielj.com

Vol-3,Issue-2,2020

ISSN:2581-6500

yes, perhaps ,many left out names in

poetry, might appear more authentic and powerful contemporary voices."(1).At another place he simply annotates the difficult nature of his scholastic project he has undertaken-"True, no book or critic of Indian English Poetry can claim to be complete, for the simple reason that by the time one is writing or binding up discussion ,there may appear some new signatures in such a culturally varied and geographically vast country."(2) It clearly reveals the exhaustive and onerous nature of his work or the obvious pains he has undergone while arranging material for this critical narrative of History Of Indian English Poetry.

But, what quickly draws the attention of discerning readers is " Introduction " as mentioned above and "Epilogue " that appears on page-665 and terminates on-726, covering in total 62 pages .The "Introduction" provides laconic and immensely pleasing encapsulation of historical development encasing broader spectrum of surly ruling elite and native voices rising against them. Whereas, the literature and poetry that collided with independence conspicuously structures ironic undertones ,biting wit, insincerity and hypocrisy .Therefore, it purportedly draws together native feelings of insurgent uprisings invariably imbued with patriotic vigor and nationalistic altruism .The English creative writings of Indians of this period though not full-grown yet have a peculiar knack with graceful and innovative trialing and rhythm .Moreover, effortless handling of English language ,natural command over syntax is simply perceptible in ingenuous idioms typically Indian in itself. The author goes on further expounding the progression of national movement till it assumes the form of spiritual revolution by the purposeful participation of saintly figures.

The committed precursors of R.N.Tagore ,Vivekanando ,Sri Aurobindo ,Joseph Furtado and many of their dedicated successors accomplished remarkably superb mission. As it was an age of metaphysical and eschatological deliberations we often see some such elements overriding the scenario of fictional and poetic genus. Changing national turmoil further seems to disrupt the literature of the age. Diverse brands of voices from different regions of the country produced versatile poetry, against existing social ,political ,economic ,religious, philosophical and patriotic backdrop. Deeply ingrained in native soil, these voices gain steady strength and length, and in due course of time, succeed in forming a supplementary to the movement- national as well as literary .

In this way,the most relevant and intriguing critical evaluative narrative deliberates to enter into the emergence of urban-town- rural clash.This mutual incongruity moves ahead to stir and beget two major thought patterns. One is captioned 'Cynicism and Anguish' and the other 'Hope and Anticipation '.Both uninterruptedly spin and gyrate around life and existence and ways of living. Apart from analyzing prevalent literary trends, the author goes through new-fangled whims floating alongside the oncoming spewing currents. This is what lends special probe to his history and aesthetics of probity. Over and above all, history 
VS Publications

Alford Council of International English \& Literature Journal(ACIELJ)

Impact Factor:4.401(SJIF)An International Peer-Reviewed English Journal

www.acielj.com

Vol-3,Issue-2,2020

ISSN:2581-6500

counts a good deal besides constituting major part of poet- critic's exonerating rubrics .Hence it is, what he infers to offer successfully, after protracted and painstaking study, to his favourite readers ,creative writers and critics of Indian English Poetry.

The Epilogue forming another hub eagerly documents a consummate review of critical works of prominent authors,editors, academics and critics .In order to entertain historical value, the author plainly asserts-he has included not all but a few leading names whom he categorize as -1.Critics. 2.Editors. The foremost lacunae overtly pointed out is unavailability of creative works of lesser known poets because of indifferent attitude of publishers and the difficulty of having easy access to Poets on individual basis. This setback puts the critic in petty-little doldrums .Moreover ,to administer organized growth and development of Poetry age-wise and decade-wise is not a piece of cake for the scholar-critic. As far as, possible inclusion of individual poets is concerned,the appearance of quite a good number of anthologies on multi-hued scene of Indian English Poetry today ,avers the critic, is not only a positive sign but also an encouraging effort .While frequent reviews, evaluation and feedbacks by many inquisitive scholars and questioning minds of/on the creative works is an admirable step taken towards recognition-applause as well.

Togetherness is one more interesting and inspiring feature that has helped largely in the growth of literary activity. Mostly group-activity inspires academicians or lovers of literature to edit a Journal or to publish a book .Many excellent works on poetry and criticism are readily noticeable as products of joint venture. Prof .P. Lal's Writer's Workshop ,was the first of its kind, to serve and encourage the then many old and budding new poets, aspiring subsequently for a name and the fame. Almost all literary Journals devoted to poetry and criticism ,published up-to-date, find a place of pride through briefest assessment in this life-size volume/s. The writer then opts for evaluation some selected works on literary criticism .The first coming to fore, is Bijoy Kumar Das's 'Modern Indian English Poetry'.It examines critically and analytically some prominent poets like O.P.Bhatnagar and those of his ilk. Next he opts for a well known surveyor M.K.Naik's noteworthy project ' $A$ History Of Indian English Literature' that adequately throws ample light on the primacy of British rule, its indelible impact on social ,cultural, educational and philosophical expanse of India. Then the Gandhian Whirlwind and the consequent aftermath .

$\mathrm{He}$ adds to tell that the book includes an impressive and select Bibliography to help the researchers in finding newer pastures for further research for it integrates enough of material to superintend .There onward, he takes for consideration Bruce King's major treatise 'Modern Indian Poetry In English 'that chiefly yet meaningfully deals with urban poetry's cultural ,historical ,sociological and literary drive and drift. The poets studied form an elite circle of highly educated intellectuals like 
VS Publications

Alford Council of International English \& Literature Journal(ACIELJ)

Impact Factor:4.401(SJIF)An International Peer-Reviewed English Journal

www.acielj.com

Vol-3,Issue-2,2020

ISSN:2581-6500

Nssim Ezekiel,Shiv

K.Kumar,Mahapatra,Parthasarathy and many more.Above all the book is ,as it really is , an excellent bundle of brilliant thoughts and ideas. Before taking his own book 'English Poetry In India-A Comprehensive Survey Of Trends And Thought Patterns', he has skillfully studied for evaluation two more books .One is Satish Kumar's 'A Survey Of Indian English Poetry'-a successful survey,as the critic avers, with a few inadequacies .The other 'Origin ,Development And History Of Indian English Poetry'-a joint effort of Iftikhar Hussin Rizvi and Nasreen Fatima Rizvi.The book under review mainly centers around literary as well as intellectual spheres pleasantly exposing the policy of inclusion/exclusion phenomenon. The review articles of D.C.Chambial , K.V.Dominic and O.P.Arora on PCK Prem further add flavor and fragrance to I.E.P. Thereafter, Sudhir K. Arora's massive and surprising 5volume production 'Cultural And Philosophical Reflections In Indian Poetry In English'-an exhaustive evaluation of Pre and Post Independence Indian English Poetry with an elongated Bibliography to help budding researchers .Not to give much weight to, PCK Prem's 'A Study Of Ten Poetic Minds In English Poetry In India', T.V. Reddy's UGC Project 'A Survey Of Indo-English Poetry' unsurprisingly skips to trace excellently the historical and cultural interaction of Indian elite with increasing Western influence on/of language, prosody and lifestyle. This work indeed allocates T.V.Reddy an estimable place of pride in the emerging realm of Indian English
Criticism. Next ,PCK Prem selects to give out briefer judgments on edited PoetryAnthologies respectively ,such as-V.K.Gokak, Pritish Nandy, R.Parthsarathy, H.S.Bhatia ,Niranjan Mohanty, D.C.Chambial, S.N.Joshi ,Syed Ameeruddin ,K.Ayyappa Paniker and PCK Prem.

Another interesting feature of this two volume history of Indian English Poetry is that it devotes separate database to Women Poets. Volume-II of the Book presents a survey of Contemporary Indian English Women Poets one by one in Part II .This study admirably narrates against historical setting, gradual progression ,growth, diversion and digression Indian English Poetry is accompanying with changing times and ethos under five separate Chapters-from VII to XI. Chapter VII entitled 'Women Poets' houses all but shrewd analysis of women poets from $19^{\text {th }}$ century to present. Remaining subsequent Chapters study individual poets. Thus Chapter VIII studies 12 major poets under the heading-'Poetry of ethical strength and modern sensibility'. Chapter IX ,begins with the First Decade of $21^{\text {st }}$ Century .It overall critically evaluates nine poets. Chapter X captioned-'Continuity in enigmas of life and realities' incorporates 13 poets. While Chapter XI examines 16 poets under the title-'Contemporary Consciousness and Cultural Heritage'. Truly speaking, all prevalent propensities, drives and drifts, movements and fads visible in contemporary world, together with matter-of-fact idiom and phrase, outlandish or indigenous images, crystalclear figures of speech and trope, all at once add beauty and benefit to author's 
VS Publications

Alford Council of International English \& Literature Journal(ACIELJ)

Impact Factor:4.401(SJIF)An International Peer-Reviewed English Journal

www.acielj.com

Vol-3,Issue-2,2020

ISSN:2581-6500

unmatched critique-his intense probe into new dawns and horizons.

But what pleases and teases most, as the author retorts, at several occasions ,is primarily the growing challenge of contemporary spells. The changing scenario of the eon, its sick hurry and divided aims of life, prompts to incite,stir up and dislocate all available resources to further diminish and inhibit steady flow of life. Another dynamic is that we have lost most of our well-mannered, modest and ethical values essential for a vital approach to the sphere of reason and common sense. That is why, the innate urge to thrive inward, bloom and flower needs to be cheered to further exude beauty ,goodness ,innocence, sensitivity and sentimentality. The struggle to find respite, coziness and security amidst increasing intolerance, frowning temper tantrums and the unspoken bitterness in/of life remains only an experience the poets of the age depict.

The main constituent that imparts strength, zeal and appeal to the book, is its ability to evolve, a new critical rubric, an evaluative diction unobserved so far. Another area of expertise shows that each Chapter has an unsullied concept for further elaboration also to accentuate poet/s individual trait. Volume - I, comprises 14 such chapters. Here we have 14 concepts their scope elongated as per poet's lyrical, cynical ,rhythmical or eccentric nature .To begin with, the book opens to surmise growth of Indian English Poetry, particularly early phase, that happens to had a tremendous drive on socio-religious movements. British inkling on literary scenario is fairly implicit. Likewise, the churning of the times, gives impetus to religious movements
culminating in sturdy nationalism.

Almost all poets share the same anxiety and concern, the same distinctive spirit of universal love and brotherhoodVasudhaiv Kutumbakam .Once again, the author shifts his ante, to socio-political awakening ,spiritual and mystical quests and unmitigated sufferings of man and his ilk .The era being pre-independence, the author eloquently speaks about rebellious riots ,furor shaking the nation and independence gaining momentum . The ire, resentment and unfulfilled craze is clearly visible in literary output simultaneously. The whirlwind of Gandhian movement besides gaining strength fortifies to put up strongholds . The literary scene, postindependence, looks flooded with quest for unity, discovery of roots related to traditional cultures, customs based on beliefs and religious superstitions spread over India from times immemorial..A little before 1920 and after independence upto 1980 the poetic scene as mentioned above ,looks fairly overcrowded. National consciousness and chaotic events taking place the world over considerably influenced the stature of existing poetry .This was the epoch India saw the spread of renaissance, romanticism and tendencies pertaining to reformation. It is all about the things those came to set the tone and timbre of Indian English Poetry. Under the theme' Continuity in thought patterns strengthens consciousness 'poets born between 1921-24 are evaluated in 48 long pages. While analyzing personal traits of poets ,the critic invents a peculiar mode, that gives vent to tendencies, situations ,unreciprocated questions, intellectual 
VS Publications

Alford Council of International English \& Literature Journal(ACIELJ)

Impact Factor:4.401(SJIF)An International Peer-Reviewed English Journal

www.acielj.com

Vol-3,Issue-2,2020

ISSN:2581-6500

responses of poets concerned and finally the challenges those confront with doubts and cynicism, hope and aspirations of life .And further justifies his critique by using quotes from the texts.

This mode of exploiting critical tenets deserves merit .Another title'Steady thought patterns and perception' studies in 61 pages some major poets like P.Lal, Bhatnagar ,Mahapatra etc ,etc, born between 1926-29. 'Religious-secular thought and universality' critically examines in 42 pages, poets born between 1932-

\section{O.P.Bhatnagar,I.K.Sharma,Baldev}

Mirza, Arun Kolatkar and Som.P.Ranchan move round around the circle. 'Secular ambiance and anxiety' deals with poetic propensity of poets such asK.Das,R.Parthsarathy,H.S.Bhatia,K.B.Rai and others all born between1934-36 in 53 pages. The segment 'Towards Indian consciousness' discusses under stern critical canons the achievements of Iftikhar Hussain Rizvi and many others. 'Steadyness in thought patterns' surveys rather succinctly the credentials of poets such as-Keki N.Daruwalla,Dom Moraes, V.V.B Rama Rao ,Kailash Ahluwalia and others- born between1937-38. 'Continuity strengthens consciousness' explores poets born in 1940 like-Aju Mukhopadhyay, Yayati M.Gandhi,Adil Jussawalla,Eunice de souza and many others. 'Realization and stability' talks about P.K.Majumder,Syed Ameeruddin, Mohammed Fakhruddin and many more of their ilk. 'Regions of nearly idealistic and meaningful existence' within this title are ensconced comfortably -T. V. Reddy ,A.N. Dwivedi ,O .P. Arora,
R.C.Shukla and others. 'Consciousness and Realization 'concentrates on the study of poets born between 1944-48.Nardeo Sharma,PCK Prem,Pritish NandyA.K.Mehrotra,Hoshang

Merchant,Jasvinder Singh and many others share the platform together.Then comes the last segment 'Possible Stability and judgement' that includes poets born between1949-50 comprising the analysis of poets like

S.L.Peeran,D.C.Chambial,R.K.Singh,Vija y Vishal and many others.

Volume II ,deals with trends, movements,predilections and aspects of both rural as well as urban poetry, alongside individual poets born in 1950 and after, indeed, to give his narrative a chronological flavor and fragrance .However , unlike the first ,the second volume is divided into two major parts-I $\&$ II. The major trends and poetic proclivities with changing times are studied extensively against historical ,multi-cultural and multi-lingual setting of the country .While the poetic chain incorporates small town, urban and rural terrains and landscapes in particular. The strengthening of consciousness, Power of realization ,Poets \& regions of perception , Continuity in perspectives with some variations, Understanding teaches art of life and A change in thought \& emotions beautifies lyrics - these are some such subtitles the poets of their respective age decade-wise find right place to be exonerated with available literary injunctions .

There is too much erudition and profundity involved in assigning appropriate status to the poets as per s/he's creative oeuvres. There is too much scope 
VS Publications

Alford Council of International English \& Literature Journal(ACIELJ)

Impact Factor:4.401(SJIF)An International Peer-Reviewed English Journal

www.acielj.com

Vol-3,Issue-2 ,2020

ISSN:2581-6500

in the volume for further study of such rubrics, but I avidly with elation wind up my analysis without going ahead. What deserves appreciation is authors's motive of congregating diverse trends of Indian culture ,ethos ,urbanity, philosophies ,traditions ,emotional apprehensions ,hollowness of dreams ,realities and beauties in a single strand.All flows together as one in many and many in one to winch tremendous colors of unity .The oft used dictum 'unity in diversity' thus genuinely justifies author's indefatigable efforts, those will never go in vain, as the book has enough material ,motto, exalted syntax ,amazing diction, narrative proficiency, poetic beauties and rare profundities .After all, as mentioned above, poetry concentrates on chastity of consciousness by distilling unnecessary gross and dross that hampers inner flowering. The gift of lively sensibility, wider knowledge and 'esemplastic imagination'(3), by and large, egg on the poets to see and feel more and more in order to reconstruct a mini absolute world in varying hues, facts and facets .Next,the narrative technique employed too exudes a sense of rare wonder .Nevertheless, the book is a greater challenge to reader's sense of belief,disbelief, inquisitiveness ,quest,knowledge and power of discrimination .A deeper reading renders more meaning ,permits space for further and future probe than the apparent or preliminary cursory glance.

What is more, the 'Suggested Readings'(727-731) have enough scope to guide the pursuers, followers ,admirers and the disciples of Indian English Literature .Index(732-738) in which poet/s are placed alphabetically add another beautiful feather in the cap of the volume/s.

\section{References:}

- Mukherjee Meenakshi:THE TWICE BORN FICTION (New Delhi :Arnold Heinemann-1971).

- Prem PCK :History Of Contemporary INDIAN ENGLISH POETRY :An Appraisal ,Volume

I,Acknowledgement-7.

- Ibid........Epilogue--------675.

- Coleridge.S.T :BIOGRAPHIA LITERARIA w.https://en.m.wikipedia.org. 